\title{
HATCHING IN CALANUS FINMARCHICUS AND SOME OTHER COPEPODS
}

\author{
By S. M. Marshall, D.Sc. and A. P. Orr, D.Sc. \\ The Marine Station, Millport
}

(Plate I and Text-figs. I-5)

During observations on the development of the eggs of Calanus finmarchicus the process of hatching was watched on many occasions. Since it differs from that described by Ziegelmayer (1926) for cyclopids it seemed worth while examining the process in other groups of copepods as well.

Hatching can be followed very easily in Calanus (Pl. I). For some time before, the form of the nauplius can be clearly seen with its limbs folded close to the body (A); in many a red pigment spot develops at this time in the otherwise transparent egg. Shortly before hatching the limbs begin to twitch occasionally and a space is just visible round the body of the nauplius. At this stage the inner and the outer egg membranes cannot be distinguished, but when hatching begins, the outer membrane must crack for the delicate inner membrane bulges out (B). The bulge enlarges rapidly (C), and the nauplius extends into the bulge, sometimes leaving a clear space between itself and the membranes (D). Usually it is either the head or the tail end which pushes into the bulge, but occasionally it is a limb. Probably it is abnormal for a limb to extrude first since such eggs do not always hatch successfully. As the inner membrane expands, the outer slips back and the inner, enclosing the nauplius, pops out (E). This emergence often occurs suddenly, but sometimes it is gradual (as in E), when the outer membrane crumples up on the inner, regaining its original shape only when the inner has slipped out and the tension is released $(\mathrm{F})$. The inner membrane now forms a perfect sphere of much greater diameter than the original egg.

During the first part of the hatching process the nauplius continues to twitch at irregular intervals. After it has emerged in its inner membrane, it has a considerable space round it, and it then begins to stretch out its limbs and become more active (G). Quite suddenly it tears the membrane and swims away $(\mathrm{H})$. The diaphanous remains of the inner membrane are hardly visible. The whole process takes about IO-I $5 \mathrm{~min}$ at room temperature $\left(\mathrm{I} 5^{\circ} \mathrm{C}\right)$, but the time spent in each stage is variable. Sometimes longer is spent in hatching from the outer membrane and sometimes longer from the inner.

Since the diameter of the egg is $145 \mu$ its volume is about $0.0016 \mathrm{~mm} .^{3}$. Two eggs, in which the inner membrane was measured immediately after slipping 
out, had diameters of $19 \mathrm{I}$ and $209 \mu$, the volumes being now more than double, 0.0037 and $0.0048 \mathrm{~mm} .{ }^{3}$ respectively. The diameter increased and was measured again just before the nauplius escaped, when it was for both eggs $244 \mu$, giving a volume of $0.0076 \mathrm{~mm} .^{3}$ or nearly five times the original. The surface area had therefore increased 2.8 times. One nauplius was measured a few minutes after hatching and was $174 \mu$ long, i.e. larger than the original diameter of the egg.

Osmotic hatching has been suggested in a number of Crustacea (see Yonge, 1937), and we therefore examined the possibility in Calanus eggs. Twentynine eggs near hatching were used for the experiment; fourteen were kept in normal sea water as controls and fifteen in sea water to which a small quantity of fresh water was added. In the controls three bulged and hatched successfully; in the fifteen which were treated experimentally, eleven bulged although only seven of these hatched successfully. It is obvious, therefore, that osmosis may be an important factor in hatching. If fresh water is added some time before the nauplii are ready to hatch, the egg ruptures, extruding a mass of tissue, but the inner membrane does not appear at all.

C. helgolandicus eggs hatch in exactly the same way. In another very similar form of Calanus, found at Tromsø (Marshall, Orr \& Rees, 1953), eggs are laid which produce, shortly before the first division (possibly on fertilization), an extra, thin, irregular, membrane separated by a varying space from the original egg. Hatching of these takes place in the same way as in other Calanus.

The eggs of Metridia longa and Acartia clausi also hatch in this way. In Acartia the outer membrane seems to be relatively more rigid than in Calanus. It does not crumple, but splits and slips off by gaping wider. The inner membrane also seems relatively thicker since it is quite clearly visible after the nauplius has left it. Shortly before hatching a rosy tinge becomes visible over about half the egg, and in the hatched nauplius the tips of the antennules are pink. The eggs measure $77-78 \mu$ before hatching begins, and in one the inner membrane just before the nauplius escaped had swelled to $129 \mu$ thus increasing the volume four and a half times.

\section{EXPLANATION OF PLATE I}

A. Egg of Calanus finmarchicus shortly before hatching showing the nauplius form.

B. The inner membrane begins to bulge. The outer membrane has a diatom chain attached which can be seen throughout the rest of the series.

C. The bulge of the inner membrane is growing rapidly.

D. The nauplius inside the inner membrane is emerging from the outer.

E. The outer membrane has crumpled up and the diameter of the inner membrane much exceeds that of the original egg.

F. The outer membrane has sprung off and has partly regained its spherical form. There is a large space between the nauplius and the inner membrane.

G. The nauplius stretches its limbs.

H. The nauplius is swimming away and the remains of the inner membrane can be faintly seen, indicated by the arrows. 

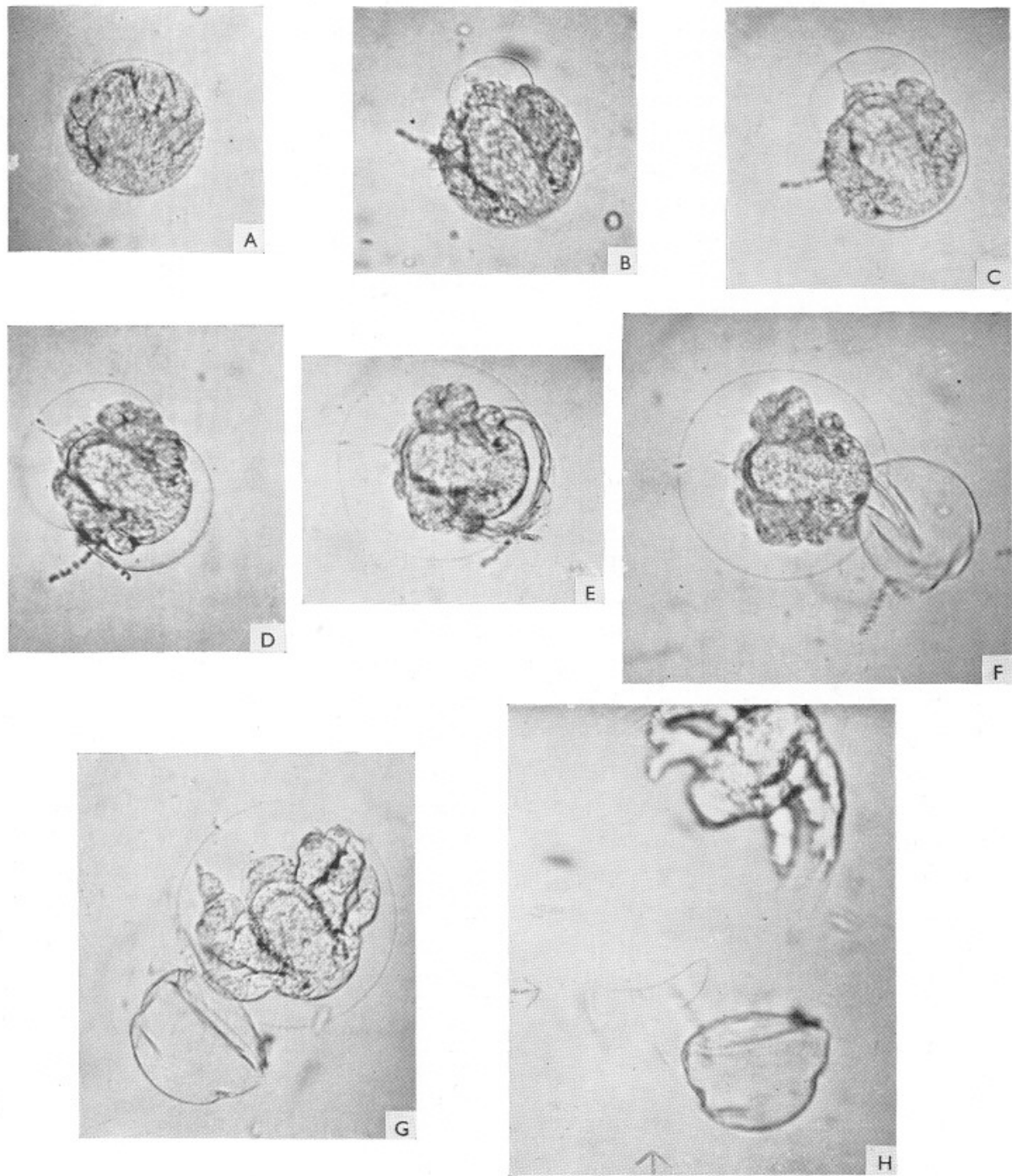
All these copepods liberate their eggs directly into the sea. Others, however, carry them in sacs attached to the genital segment, and several of these species were observed to see how hatching takes place.

The female of Pseudocalanus minutus carries a mass of eggs varying in number according to the season from about io to 28 (Marshall, 1949). As the eggs develop they get darker in colour, and in some a red pigment spot is seen. The process of hatching is much the same as that already described; the outer membrane cracks, the inner membrane bulges out and eventually the nauplius comes out (Text-fig. I). Usually, however, the inner membrane does not come completely free from the outer before the nauplius struggles and breaks it.

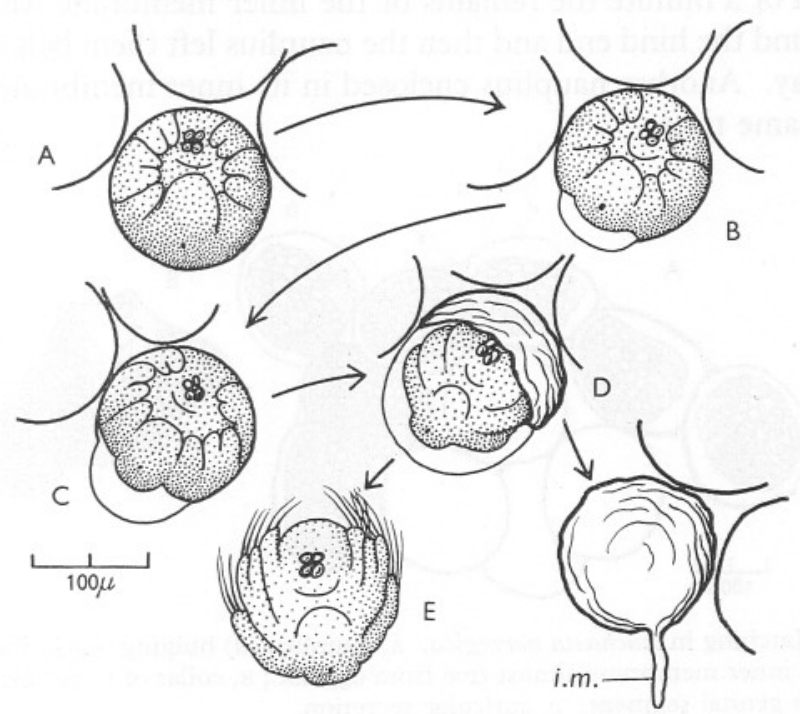

Text-fig. I. Hatching in Pseudocalanus minutus. A, egg shortly before hatching; B, inner membrane beginning to bulge out; $\mathrm{C}$, a later stage; D, outer egg-membrane crumples up and nauplius emerges in inner membrane; $\mathrm{E}$, nauplius escapes and inner egg membrane (i.m.) is left attached to outer.

The torn inner membrane usually remains attached to the outer. Once the inner membrane enclosing the nauplius came right out and floated away. It swelled until there was a space round the nauplius but this egg failed to hatch. The eggs before hatching measured between $\mathrm{I} 20$ and $\mathrm{I} 40 \mu$ and the inner membrane increased up to $\mathrm{I} 60-\mathrm{I} 70 \mu$ in diameter, an increase of a little more than twice the volume. The swelling is therefore not so great as in Calanus. Although the egg-mass often looks as if it were contained in an actual sac, when the nauplii have hatched out it seems to be composed only of individual outer membranes stuck together.

Euchaeta norvegica is a large copepod living in deep water and it does not survive well under laboratory conditions. The eggs when first laid are deep 
blue in colour, and according to Nicholls (1934) a normal egg-sac contains about 50 eggs. Development is slow, and the interval between laying and hatching is at least 8 days compared with the $24 \mathrm{~h}$ normal for Calanus. It was therefore not unexpected that the process of hatching should be prolonged. As development goes on the eggs change in colour from dark blue to reddish brown, and the body of the nauplius is seen to be full of fat globules. As usual the outer membrane eventually cracks and the inner membrane bulges out (Text-fig. 2A). Nauplii may remain in this condition for many hours. On one occasion a nauplius had broken its inner membrane and was partly hanging out, twitching actively, when a sudden jerk on the part of the mother threw it right out. For a minute the remains of the inner membrane were to be seen clinging round the hind end and then the nauplius left them behind and swam actively away. Another nauplius enclosed in its inner membrane was thrown out at the same time.

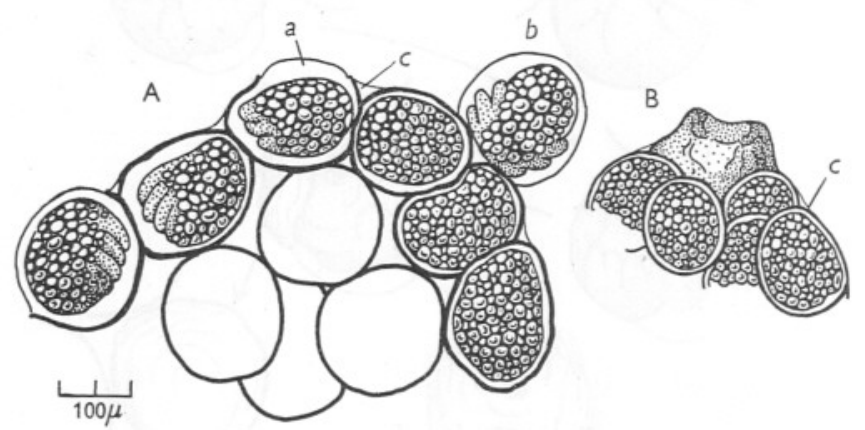

Text-fig. 2. Hatching in Euchaeta norvegica. A, nauplius (a) bulging out in inner membrane; and $(b)$ in inner membrane almost free from egg-sac; B, collar of secretion which attaches egg-sac to genital segment. $c$, cuticular secretion.

One female in which the eggs were hatching was kept overnight. In the morning there were about twenty-two nauplii in the surrounding water, most free and active but several enclosed in their inner membranes. They remained like this for some time and actual hatching was not seen. In detaching an eggsac from a dead female a number of nauplii, some in the inner membrane and some free, were shaken out, and it seems likely that the movements of the mother play an important part in helping the nauplii to hatch. The egg-sac, which is flattened in form, is attached to the genital segment by a projecting collar of secretion (Text-fig. 2B).

In the cyclopids the eggs are carried in paired sacs attached to the genital segment. In Oithona similis the egg is oval, the diameter varies from 70 to $95 \mu$, and each sac contains from five to eighteen eggs according to the season. The process of hatching is not so easily followed as in a larger egg, and there are several differences from Calanus. When the outer membrane cracks the inner 
membrane cannot be seen bulging out. It envelops the nauplius much more closely than in Calanus, and the only sign of the outer membrane rupturing is a sudden stretch on the part of the nauplius up to $105 \mu$ or more. After a short time the nauplius slides forwards and pushes well out of the outer membrane, sometimes twisting round as it does so. A female has been seen swimming about with the nauplii hatching and hanging out in all directions round the egg-sac. The inner membrane cannot always be made out at this stage, but is seen most clearly when the nauplius is viewed from the side. After quite a long pause, during which the nauplius twitches frequently, it stretches out its limbs (which up till now have been close to the body) and struggles to get its spines loose. When it finally breaks free and swims off, the inner membrane is usually left attached to the outer.

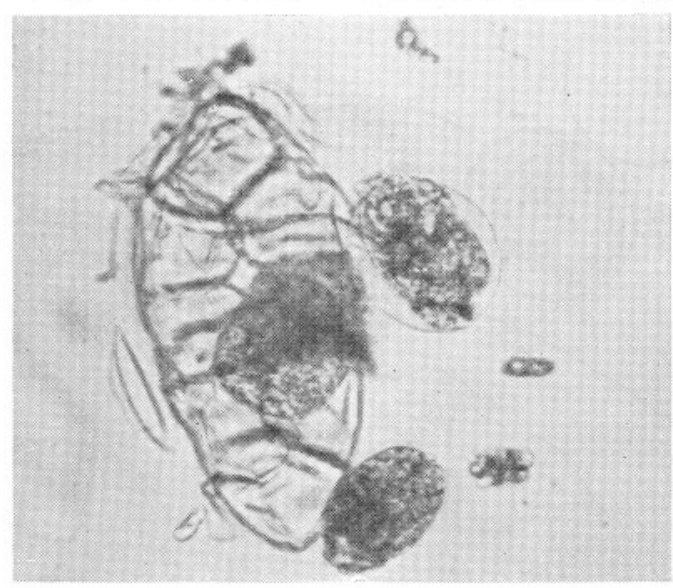

Text-fig. 3. Photograph of the egg-sac of Cyclops agilis. Most eggs have hatched, leaving the inner membranes hanging on to the outer. A nauplius still in its inner membrane is seen on the right.

In the freshwater copepod Cyclops agilis the eggs measure 90-110 $\mu$ in diameter. The nauplius was not seen to twitch before hatching. When the outer membrane cracks the inner membrane bulges out for an instant and then almost immediately slips right out, although still remaining attached to the outer. It fits the enclosed nauplius fairly closely; it is not spherical and can be seen most clearly when the nauplius is viewed from the side, for although touching the head and tail it is well separated dorsally and ventrally (Text-fig. 3). Very little swelling takes place, the maximum diameter being only $\mathrm{I} 20 \mu$ and the volume is thus only doubled. After a few minutes, during which it twitches occasionally, the nauplius gives a violent movement, breaks out and swims away, almost always leaving the inner membrane attached to the outer. The inner membranes seem to be relatively thicker than in Calanus 
and, after all the nauplii have hatched, they can be seen hanging out all round the egg-sac.

In Cyclops viridis, another freshwater copepod with eggs about $130 \mu$ in diameter, hatching takes place more slowly. The inner membrane bulges out (Text-fig. 4A) and, as it swells, the outer membrane can be seen crumpling up (Text-fig. 4B), as it sometimes does in Calanus (Pl. IE), springing back to its original shape when the nauplius pops out in its inner membrane. This stretches to contain nearly four times the original volume and, as it does so, the nauplius increases in size so as to fill it completely (Text-fig. 4C). When the nauplius breaks out and swims away, it usually leaves the inner membrane attached to the outer (Text-fig. 4D), but sometimes leaves it free in the water. All the eggs in one egg-sac hatch at practically the same time, and the violent movements of the hatching nauplii jerk the detached egg-sac about.

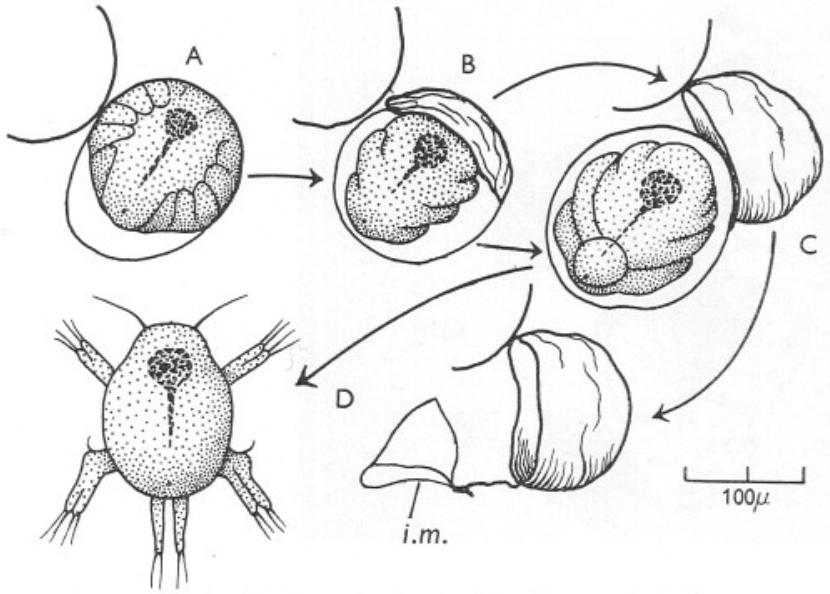

Fig. 4.

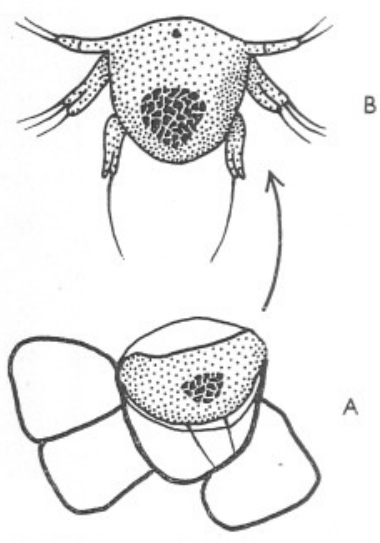

Fig. 5 .

Text-fig. 4. Hatching in Cyclops viridis. A-C, stages in hatching; D, nauplius and egg-shell with inner membrane (i.m.) still attached.

Text-fig. 5. Hatching in Tigriopus fulvus. A, the nauplius bulging out in its inner membrane; $\mathrm{B}$, nauplius showing the long mandibular spines.

A harpacticid Tigriopus fulvus was also observed. There is a single egg-sac and, as in Cyclops viridis, the eggs all reach the hatching stage at about the same time. The nauplii twitch occasionally for about an hour before emerging. The outer membranes crack, the inner membranes bulge out, and in a short time the whole sac is covered with nauplii hanging out in their inner membranes (Text-fig. 5A). A curious feature is that the long mandibular spines seem to extend beyond the inner membrane and remain attached to the inside of the outer membrane. The inner membrane disappears suddenly, but whether it bursts or whether the nauplius increases to fill it completely is uncertain. The 
nauplius is still firmly attached by the mandibular spines and violent struggles are necessary to detach them. After all the eggs have hatched a few inner membranes are seen hanging on the outer membrane, but they are not so many nor so distinct as in Cyclops.

In the semi-parasitic copepod Caligus rapax, the egg-sacs are each formed of a long row of single eggs one behind the other, and hatching takes place in the same way. The eggs hatch successively from behind forward and each bulges out in the inner membrane for a few minutes before breaking out and swimming off. According to Mr B. T. Hepper of the Burnham-on-Crouch Laboratory (personal communication) the eggs of Mytilicola intestinalis, a copepod parasitic in mussels, hatch in a rather similar way.

\section{DisCUSSION}

It is clear that in all these copepods, belonging to several different groups, hatching takes place on the same general plan. As development goes on there is often a colour change in the nauplius (Calanus, Pseudocalanus, Euchaeta, Acartia), and this is sometimes the first sign of hatching. The rigid outer eggmembrane is first burst by the pressure inside the inner membrane. This inner membrane, enclosing the nauplius, then emerges from the outer membrane, but it may do so gradually as in Calanus or very quickly as in Cyclops agilis. The increase in volume which takes place inside the inner membrane varies with the species. In Calanus the volume increases about fivefold before the nauplius hatches, but in eggs which are carried in egg-sacs the increase is usually much smaller and sometimes may be little more than is necessary to crack the outer shell. In some, e.g. Calanus, there is a large clear space round the nauplius after it has slipped out, while in others such as Oithona the nauplius fills the inner membrane completely; the other cyclopids are intermediate in that they seem to fill it when viewed dorsally or ventrally but not when viewed laterally. In both types the nauplius stretches or imbibes water before tearing the inner membrane, but the first does so at a later stage than the second.

In those copepods which lay eggs freely in the sea (Calanus, Metridia, Acartia) the inner membrane separates completely from the outer, but in those hatching from egg-sacs it more commonly remains attached. This may help the nauplius to avoid entanglement. It is not clear how the inner membrane stays attached, for it often (see Text-figs. 3 and 4) seems to come right out of the outer. Euchaeta norvegica is a copepod which shows both methods. Some of the nauplii in their inner membranes come out quite clear of the egg-sac before hatching, while others leave their inner membranes attached. The movements of the female in this and other copepods may have some effect in helping nauplii to escape from the egg-sac.

A puzzling feature is that in Oithona and Tigriopus the spines seem to extend through the inner membrane. This follows the outline of the nauplius body 
when the latter is hanging out from the outer shell, but the spines project beyond it and seem to be attached to the inside of the outer membrane (see Text-fig. 5A). The nauplii have a considerable struggle to release the spines before they escape.

Ziegelmayer's (1926) observations on the hatching of seventeen species of cyclopids differ considerably from ours. According to him it is the outer eggmembrane which swells. This process may take $\mathrm{I} 4 \mathrm{~h}$ or more. A pressure develops in the space thus formed between the outer and the inner membranes. The outer membrane eventually bursts and the inner, in which the nauplius is tightly enclosed, emerges. After a short time the nauplius moves its antennae, tears the inner membrane, and escapes; it then remains still for Io-20 sec, begins to move its limbs, and finally swims off.

According to our observations, however, it is the inner membrane and not the outer which expands. It is difficult to decide whether Ziegelmayer was unable to see the bulging out of the inner membrane or whether the specimens he examined behaved in a different way. The eggs in his two photographs, taken after 3 and io h swelling, are, when we allow for the different magnifications, very much the same in diameter, and the second resembles a nauplius released in its inner membrane.

That hatching may be an osmotic process is suggested by the few experiments on Calanus eggs described above, and this has been found also in cyclopid copepods by Ziegelmayer (1926), and in several other Crustacea-e.g. in Hemimysis by Manton (1928), and in Daphnia and Simocephalus by Przylecki and Ramult (Needham, I93I).

A possible explanation of the mechanism of hatching might be that a sudden increase of excretion by the embryo leads to an increased content of salts and the imbibition of water. It is noteworthy that in nearly all species twitching of the nauplius begins shortly before hatching. It is difficult, however, to understand how osmotic control can be effective in Tigriopus, which lives in shore pools and is therefore subject to considerable variations in salinity.

In the eggs of decapods (Yonge, 1937, I946) there are two membranes, a cuticular, secreted by glands on the pleopods of the female, and a chitinous, secreted by the oviduct. According to Herrick (1895), the cuticular membrane splits at hatching and completely separates from the underlying membrane except at one point. This underlying membrane (presumably the chitinous one of Yonge) is now greatly distended and from it the young lobster hatches.

In most copepods that bear egg-sacs only two membranes are visible. Euchaeta norvegica is the only species we have used that is large enough to give clear results with chemical tests. In it the mass of secretion joining the egg-sac to the genital opening, together with the material connecting the eggs (Text-fig. $2 \mathrm{~B}, c$ ), has been shown to be cuticular in nature. This cuticular secretion presumably also surrounds each egg. In Caligus (Wilson, 1905) cement glands are present which secrete the egg-sac and also a covering round each egg. 
It seems most probable that in the copepods the two membranes we have described as outer and inner correspond to the cuticular and chitinous membranes in the lobster, the chitinous one being extensible.

An alternative explanation might be, however, that in copepods the extensible inner membrane is secreted by the developing embryo, and that the chitinous and cuticular membranes are so closely adherent that they are indistinguishable except possibly in Euchaeta.

We are grateful to Prof. C. M. Yonge, F.R.S., for his interest in the problems raised and especially for his help in the chemical tests. We should also like to thank Dr J. P. Harding of the British Museum for identifying the species of Cyclops, Tigriopus and Caligus, and Dr R. B. Pike for preparing the drawings for reproduction.

\section{SUMMARY}

The process of hatching is described for Calanus finmarchicus and other copepods. In Calanus the outer egg membrane breaks and the nauplius emerges enclosed in a very delicate inner membrane which swells to contain a volume as much as five times that of the original egg. The nauplius escapes by tearing this membrane. Other copepods which lay their eggs freely in the sea hatch in the same way, but in copepods that carry egg-sacs the swelling in the inner membrane is less, and when the nauplius emerges the inner membrane is usually left attached to the outer.

The mechanism of the hatching process and the nature and origin of the membranes are briefly discussed.

\section{REFERENCES}

HerRICK, F. H., I895. The American lobster; a study of its habits and development. Bull. U.S. Fish. Comm., Vol. I5, 252 pp.

Manton, S. M., I928. On the embryology of a mysid crustacean, Hemimysis lamornae. Phil. Trans. B, Vol. 216, pp. 363-463.

Marshall, S. M., I949. On the biology of the small copepods in Loch Striven. F. Mar. biol. Ass. U.K., Vol. 28, pp. 45-I22.

Marshall, S. M., OrR, A. P. \& ReEs, C. B., I953. Calanus finmarchicus and related forms. Nature, Lond., Vol. I71, p. I63.

Needham, J., I93I. Chemical Embryology. Cambridge.

Nicholls, A. G., I934. The developmental stages of Euchaeta norvegica, Boeck. Proc. roy. Soc. Edinb., Vol. 54, pp. 31-50.

WILsON, C. B., I905. North American parasitic copepods, belonging to the family Caligidae. Part I. The Caliginae. Proc. U.S. nat. Mus., Vol. 28, pp. 479-672.

YoNGE, C. M., I937. The nature and significance of the membranes surrounding the developing eggs of Homarus vulgaris and other Decapoda. Proc. zool. Soc. Lond. A, Vol. 107, pp. 499-517.

- 1946. Permeability and properties of the membranes surrounding the developing egg of Homarus vulgaris. F. Mar. biol. Ass. U.K., Vol. 26, pp. 432-8.

ZIEGELMAYER, W., I926. Untersuchungen zum Quellungsmechanismus von Eizellen. Z. Zellforsch., Bd. 4, pp. 73-122. 